\title{
Manufacturing flexibility and performance: bridging the gap between theory and practice
}

\author{
Suzanne de Treville $\cdot$ Samuel Bendahan $\cdot$ \\ Annelies Vanderhaeghe
}

Published online: 19 March 2008

(C) Springer Science+Business Media, LLC 2008

\begin{abstract}
How firms scan and interpret their environments has implications for the flexibility strategy that they choose, as well as for the performance of that strategy. We extend Daft and Weick's (Acad Manage Rev 9(2):284-295, 1984) model of firms as interpretation systems into a theoretical model of flexibility performance through extended iterations between observations of a failed flexibility initiative and relevant literature. We test the model using well-known teaching cases. We argue that the use of an iterative process that involves cases and theory both stimulates creativity in integrating theory and lays an initial foundation for evidence-based practice.
\end{abstract}

Keywords Manufacturing flexibility - Iterative triangulation methodology · Evidence-based Practice · Environmental scanning and interpretation

\section{Introduction}

It is generally agreed that the role of flexibility_defined by Upton (1994, p. 73) as "the ability to change or react with little penalty in time, effort, cost or performance" - in manufacturing strategy has substantially increased over the past couple of decades as companies respond to increased uncertainty and volatility in their environments.

When should firms consider a flexible strategic positioning? What are the factors that will increase the likelihood that an investment in flexibility will pay off?

S. de Treville $(\bowtie) \cdot S$. Bendahan

Faculty of Business and Economics, University of Lausanne, Internef 315,

Lausanne-Dorigny 1015, Switzerland

e-mail: suzanne.detreville@unil.ch

A. Vanderhaeghe

Picanol Group, Ter Waarde 50, Ieper 8900, Belgium 
Answers to these questions have remained elusive because of the fuzzy and multidimensional nature of flexibility as a construct. Much progress has been made during the past two decades in defining flexibility, differentiating it into subconstructs, and developing some understanding of the factors that are causally related to effective flexibility. In spite of this progress, however, the road to flexibility is far from easy for many companies. Upton (1994, p. 73, 1995b, p. 76) suggested that existing flexibility theory was not being fully transferred to practice, noting as well that flexibility failures were frequent:

Managers at many of the plants I studied deemed an astounding $40 \%$ of flexibility-improvement efforts to be unsuccessful or disappointing. In the vast majority of those cases, the cause could be traced to a failure to identify precisely what kind of manufacturing flexibility was needed, how to measure it, or which factors most affected it.

This paper has two objectives. The first is to extend Daft and Weick's (1984) theoretical model-linking how organizations scan and interpret their environments to how they set strategy and make decisions-to the context of flexibility. How do organizational scanning and interpretation influence flexibility outcomes, that is, changes in competitiveness or profitability that result from their flexibility initiatives?

The second objective of this paper is to strengthen the link between theory and practice in the area of manufacturing flexibility, consistent with recent calls for an increase in evidence-based practice in management research (Rynes et al. 2001; Rynes 2007). (See also Raj et al. 2007, who noted a large gap between research and practice in the implementation of flexible automation.) Consider a firm that is deciding whether to invest in flexibility. How accessible is the body of literature to that manager? We not only integrate existing theory but also explicitly attempt to bridge the "considerable chasm between research and practice in management" (Rynes 2007, p. 985). Melnyk and Handfield (1998, p. 311) stated, "The fundamental goal of any researcher is to create knowledge. By knowledge, what we mean is structured information that is readily accessible." Structuring information and making it accessible to practitioners, therefore, is as integral to research as the original production of information.

In the light of this criterion, we may question the knowledge creation process in the field of OM. As in management in general (Rynes et al. 2007), much OM research stays in academic journals in a form that is not always readily accessible to practitioners, while much practice develops without taking advantage of the results of this research (e.g., Amundson 1998; McKay et al. 2002; Linderman et al. 2003). Evidence-based practice will require that theoretical information be transferred, known, and used by practitioners, and that academic researchers explicitly consider the challenges faced by companies in defining their research (Cohen 2007).

Cascio (2007, p. 1009) commented,

Academics take pride in using the scientific method to create new knowledge. That is, they frame questions that are testable and falsifiable with data-based results. ... To academics, it is a given that theory-based, empirical data 
published in an A-level, peer-reviewed journal constitute objective, declarative knowledge that 'sells.' Major emphasis is placed on the creation of knowledge, rather than its diffusion. Academics assume that their work will be read by other professionals, including consultants and practitioners, and that the implications for the application of their findings are obvious.

Our experience indicates that an iterative process that grounds theory integration around a real company problem may be useful as one element of a move toward evidence-based practice. Our theory integration was structured around a company (that we will refer to as the "Xygma" plant to protect confidentiality) that we observed to be struggling to respond to customer demands for increased flexibility. Our observations directed our selection of relevant literature. Following the method proposed by Lewis (1998), we iterated between the company situation and the literature, forming a set of testable propositions that we eventually (after many iterations) synthesized into a model. As an initial test of generalizability, we then tested the model using three well-known teaching cases related to flexibility.

\section{Literature review}

Authors such as Zhang et al. (2003) and Koste and Malhotra (1999) have emphasized the importance of considering levels of analysis in studying flexibility. Koste and Malhotra (1999) envisioned flexibility as a cone-shaped structure, in which flexibility at a lower level supported higher-level (more strategic) flexibility. In the following sections, we review literature drawn from the strategic, tactical, and operational levels.

\subsection{Strategic flexibility}

Our analysis of Xygma at the strategic level first led us to literature concerning the fit between uncertainty in the environment and flexibility, which we later expanded to include Daft and Weick's (1984) seminal work on how organizations perceive and interpret their environment. A second issue at the strategic level concerned the valuation of flexibility.

\subsubsection{Flexibility as a response to uncertainty in the environment}

From the days when Hayes and Wheelwright (1984) suggested that manufacturing flexibility should be included as a key dimension of a firm's manufacturing strategy, researchers commonly have posited that firms increase their manufacturing flexibility to allow them to respond to uncertainty in the environment, and that an appropriate match between business strategy and flexibility improves performance (Gerwin 1993; Chang et al. 2003; Zhang et al. 2003; Sawhney 2006). Swamidass and Newell (1987, p. 521) demonstrated empirically a link between environmental uncertainty, manufacturing flexibility, and performance, commenting, "The finding that the greater the flexibility the better the performance confirms reasonable 
intuitive expectations and the literature on flexibility and uncertainty. Although this finding seems to confirm the obvious, the obviousness of the finding should not diminish its importance" (see also De Groote 1994).

Pagell and Krause (1999, 2004, p. 645), however, found a lack of fit between environmental uncertainty and manufacturing flexibility, and-even more surprisingly_no relationship between an "appropriate" match between environmental uncertainty and performance, suggesting that "the relationships between uncertainty, flexibility, and performance are much more complex than the traditional formulation found in much of the literature." In particular, Pagell and Krause noted that the firm may be able to take action to reduce environmental uncertainty through, for example, effective supply chain management (see also Handfield 1993; see also de Treville et al. 2004).

Von Ungern-Sternberg (1990, p. 360) built an economic model of the choice made by a firm between flexible capacity (able to produce two products, but at a higher cost) and inflexible capacity (able to produce only one product, but at a low cost), demonstrating that, under conditions of uncertain demand and perfect competition, the "market equilibrium (or equilibria) will always be characterized by a variety of different firms (with different degrees of flexibility) subsisting on the market." In other words, in a given market, a firm will often be able to choose either a flexible, or low-cost but inflexible, positioning, as the market is willing to reward both types of firms.

The translation of available information concerning environmental uncertainty into a manufacturing strategy begins with the collection and interpretation of data. In studying how firms evaluate their environment, we found it useful to consider Daft and Weick's (1984, p. 289) model of organizations as interpretation systems. Daft and Weick proposed that two constructs determine how organizations interpret their environment: (a) the perceived analyzability of the environment and (b) whether actors in the organization are active or passive in collecting and interpreting data about the environment. Actors are expected to respond to increased hostility in the environment by becoming more active in their environmental scanning processes. Passive actors in an environment that is perceived as unanalyzable are posited to engage in "undirected viewing," in that they tend to react to chance information, and they need to review data many times before reaching an interpretation that is generally accepted. Passive actors in an environment perceived as analyzable are expected to engage in "directed viewing," collecting large amounts of routine data and reacting to such data in a fairly traditional way. Active actors in an environment perceived as analyzable are expected to engage in "discovering," implying extended formal search intended to aid the organization in finding a single best way to respond to environmental uncertainty. Finally, active actors in an environment perceived as unanalyzable are expected to engage in "enacting," implying experimentation, testing, trial and error, and learning by doing. Rather than seeking some optimal way to respond to the environment, Daft and Weick suggested that enacting organizations actively seek to shape their environment.

The Daft and Weick model has interesting implications for flexibility research. All four types of organizations in the model are assumed to be facing environmental 
uncertainty; hence, manufacturing strategy theory traditionally has suggested that some level of manufacturing flexibility would be an appropriate response. The Daft and Weick model suggests, however, that the flexibility initiatives arising from the different types of organizations might be expected to differ substantially.

The undirected viewers might be expected to react to chance information coming from rumors or hunches, to invest relatively little in interpreting such information, and to do the minimum possible to adjust their manufacturing systems as required. These firms could easily end up over- or underinvesting in flexibility. In cases where these firms invested in manufacturing flexibility-indicating a fit between environmental uncertainty and flexibility according to the model developed by Pagell and Krause (1999, 2004) — the relationship between this fit and improved performance would be far from obvious.

The directed viewers might be expected to be relatively conscientious about collecting data about demand variability, but to evaluate such data traditionally, not seeking creative or surprising solutions. These firms might also be more likely to work to reduce environmental uncertainty than to respond to it. Such firms, if evaluated using Pagell and Krause's approach, might not demonstrate a fit between environmental uncertainty and flexibility, but they might be able to avoid a resulting decline in performance through their efforts to reduce the uncertainty.

The discoverers might be expected to conduct a thorough analysis in search of an optimum level and type of flexibility investment, working with existing or easily envisionable products and technologies. Like the directed viewers, they might be expected to control the amount of environmental uncertainty that they face rather than respond to a given amount of uncertainty. These firms would be likely to demonstrate some level of fit between environmental uncertainty and flexibility, and they might experience an increase in performance as a result.

Enactors might be expected to conduct focus groups, interview lead users (von Hippel et al. 1999), and perform technology forecasting in efforts to identify possible future states of nature, perhaps investing in attractive product or process technologies in order to shape the future. These firms might go so far as to attempt to increase the uncertainty in the environment through innovation, expecting that their manufacturing and product development capabilities would allow them to gain competitive advantage from such uncertainty. Again, these firms would be expected to demonstrate a fit between environmental uncertainty and flexibility, perhaps with the highest performance outcomes of the four types of firms identified by the Daft and Weick model.

The Swamidass and Newell (1987) study cited previously also measured the involvement of manufacturing managers in the firm's strategic decision making, finding (a) a significant positive relationship between perceived environmental uncertainty and the role of these manufacturing managers in strategic decision making and (b) a significant positive relationship between the role played by the manufacturing managers and performance. ${ }^{1}$ If the activity of the firm in scanning

\footnotetext{
1 Pagell and Krause $(1999,2004)$ did not replicate the path through the role of the manufacturing manager in strategic decision making; they limited their replication to the path from environmental uncertainty through manufacturing flexibility to performance.
} 
and interpreting the environment is related to the influence of the manufacturing function in strategic decision making, this could provide insight into the conflicting findings between the Swamidass and Newell and the Pagell and Krause studies.

To summarize, environmental uncertainty has been assumed to result in successful manufacturing flexibility, but this assumption has been called into question by the work of Pagell and Krause. Based on the model of Daft and Weick, we suggest that whether the firm reacts to environmental uncertainty by (a) responding appropriately, (b) responding in a reactive and ad hoc way, (c) or choosing to limit the uncertainty rather than respond may depend on the firm's level of activity in scanning and interpreting the environment, as well as whether the environment is perceived as analyzable.

\subsubsection{Valuation of flexibility}

How the organization values flexibility makes a substantial impact on both the level of flexibility chosen and on implementation. Use of cost-based or passive net present value analysis alone will systematically undervalue flexibility; hence, it is appropriate to conceptualize flexibility as a real option (Trigeorgis 1999). Along similar lines, Fine and Freund (1990) built a model of the economic trade-offs between the cost of acquiring flexible capacity and the benefit of being able to respond to variation in demand. Within the context of their model, Fine and Freund (1990, p. 454) were able to demonstrate that "Flexible capacity should be acquired when the expected value of its best usage in each state, summed over the states, exceeds its cost." They compared this result to a typical decision process concerning flexibility:

We are aware of a major U.S. corporation that, as part of its capacity planning process, identifies possible future states of the world, assesses the likelihood of each state, and then sets its capacities and technology plans under the assumption that the most likely state will occur. If one accepts the objective of maximizing expected profits, our model provides a clearly superior approach: the prescribed capacity and technology acquisition decision optimizes net expected benefits by explicitly hedging against the different possible states of the world. Insurance against events other than the most likely one is achieved at minimum cost (Fine and Freund 1990, p. 454).

The ability to conceptualize flexibility as an option may be linked to the Daft and Weick model of organizations as interpretation systems. The ability to consider a variety of states of nature is more likely to be found in firms whose management actively scans the environment, with passive firms more likely to evaluate only the most likely state of nature. Similarly, firms believing that the environment is analyzable are more likely to consider a restricted, easy-to-predict set of states of nature, requiring less flexibility, whereas firms believing that the environment is unanalyzable are more likely to consider a wide and relatively undefined set of states of nature, requiring flexibility. As an example, an active firm believing that the environment is analyzable might consider states of nature such as a $20 \%$ increase in product demand, whereas an active firm believing that the environment is unanalyzable might consider states of nature such as a change in the basic technology or 
function of the product. A passive firm, however, might either consider solely the most likely state of nature or instead consider an idiosyncratic set of states of nature suggested by random events such as interactions with the customer.

The value in a real option stems from the uncertainty, or volatility, that exists in a given market. We can thus distinguish between a flexibility strategy that aims to exploit rather than reduce and/or control volatility and uncertainty in an environment.

Based on the above, we extend the Daft and Weick model to the context of flexibility and include the idea of extracting value from volatility to propose:

Proposition 1 The choice of flexibility strategy (exploiting, or controlling/ reducing volatility) is related to the firm's activity in scanning and interpreting its environment, as well as whether it views its environment as analyzable. Firms that are active in scanning and interpreting the environment will tend to set a flexibility strategy that aims to reduce and/or control volatility. Firms that scan and interpret the environment actively and view their environment as unanalyzable will tend to set a flexibility strategy that aims to exploit volatility. Firms that are passive in scanning and interpreting the environment and view their environment as unanalyzable will tend to respond in an ad hoc way, rather than setting a flexibility strategy. In other words, activity in scanning and interpreting the environment determines the choice the firm makes concerning volatility-exploiting, controlling/ reducing, or setting no strategy at all-and this relationship is moderated by whether the environment is perceived as analyzable (see Fig. 1).

\subsection{Tactical flexibility}

The tactical level of analysis concerns defining and measuring flexibility, as well as the translation of flexibility at the strategic level into the technologies, systems, and structures required to realize such flexibility. This level of analysis also addresses tactics for reducing the cost of flexibility, thereby minimizing the trade-off between flexibility and efficiency.

\subsubsection{Defining and measuring flexibility}

Upton (1994, 1995b) distinguished at the tactical level between the range of products produced, the mobility of the equipment and production systems in changing from one product to another, and the uniformity of production when a change was made. Although much of the flexibility literature has tended to focus only on range, mobility and uniformity are of tremendous importance at the tactical level. Mobility is concerned with setup time reduction (which involves both equipment and workers), as well as with scheduling and with training of workers. Uniformity also is concerned with setups, as it is not uncommon for nonconforming product to be produced immediately after a setup, and with process documentation and worker training.

Koste et al. (2004) discussed the challenge of defining and measuring flexibility. They divided flexibility into six dimensions focusing on scope and achievability. They extended Upton's classification scheme by differentiating between range with respect to number of options, and range with respect to the difference between options. 


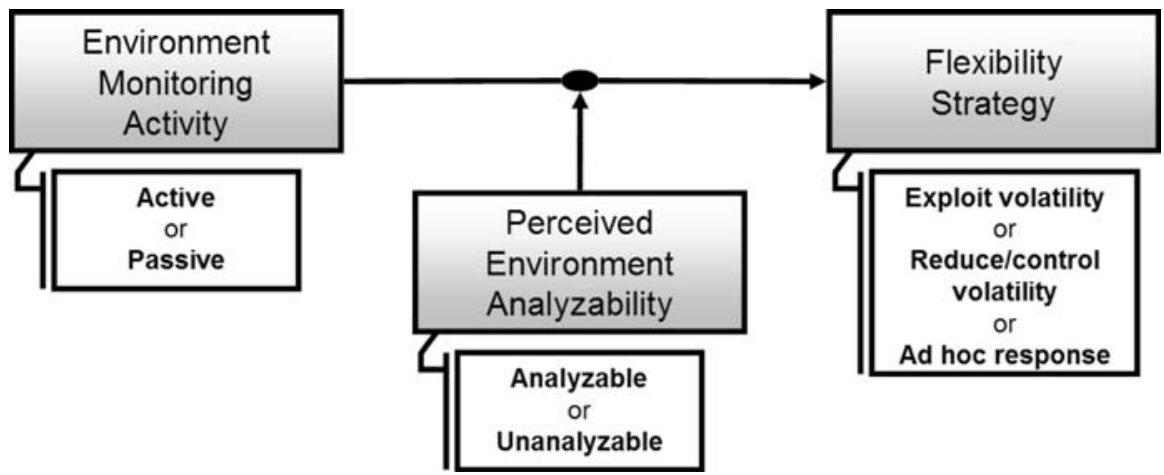

Fig. 1 A theoretical model of the relationship between environmental monitoring activity and choice of flexibility strategy, moderated by perceived environmental analyzability

Swafford et al. (2006), in their study of supply chain flexibility, claimed that the ability to switch between options is often more important than offering a large number of options. Van Wezel et al. (2006) concluded that flexibility is defined not only by hard-wired production process characteristics but also by organizational procedures in the planning process. Zhang et al. (2003) differentiated between the flexible capabilities perceived by the customer and the flexible competences achieved by the manufacturing operation.

\subsubsection{Trading off between efficiency and flexibility}

As mentioned in the preceding section, flexibility is not free of charge: Increases in flexibility often are constrained by factors such as equipment limitations, workforce experience, and quality problems from increased product changeovers (Fine and Freund 1990; Sethi and Sethi 1990; Gerwin 1993; Jordan and Graves 1995; Upton 1997). In fact, the first serious efforts to classify flexibility arose from observing the need to balance possibilities and limitations in flexible manufacturing systems (see Browne et al. 1984). Koste et al. (2004) recognized the need to trade off between the costs and benefits of flexibility in most cases. Case studies (Upton 1993/2001; Pisano and Rossi 1994; Jones 1997) give detailed examples of trade-offs and investments required by flexibility.

The traditional understanding of the trade-off between efficiency and flexibility is illustrated by the Product-Process Matrix developed by Hayes and Wheelwright (e.g., 1984). Technologies such as flexible manufacturing systems and manufacturing strategies such as lean production have as a key objective, however, to reduce the loss of efficiency resulting from increased flexibility. Authors such as Jaikumar (see also Upton 1995b), however, have argued that investment in flexible manufacturing systems and other advanced manufacturing technologies often fail to achieve the hoped-for combination of flexibility and efficiency.

Olhager and West (2002) observed that although flexibility is generally considered as a key dimension of a given firm's manufacturing strategy, the relationship between flexibility and the increase in manufacturing abilities which translate into an improved customer experience often is not obvious. Olhager and 
West noted in particular a lack of understanding concerning the relationship between manufacturing flexibility (relative to volume, mix, and new product introduction) and constructs such as cost and conformance to specifications quality. They proposed a "House of Flexibility" approach based on the well-known House of Quality (Hauser and Clausing 1988), which is designed to help firms translate market demands for manufacturing flexibility into flexible manufacturing competences, identifying trade-offs and highlighting opportunities. The Olhager and West approach is interesting because it clearly demonstrates the tremendous amount of analysis and effort required to perform this translation of market demand into flexibility competences.

Adler et al. (1999) suggested that companies could reduce the trade-off through what they called "ambidexterity": investing in the ability of employees to be both flexible and efficient. Ambidexterity included tactics such as (a) metaroutines, or routinizing innovative tasks; (b) job enrichment through adding nonroutine tasks to the operator's work; (c) switching, or dividing employee time between tasks requiring efficiency and tasks requiring flexibility; and (d) partitioning, or creating subunits in the organization specialized in either routine or nonroutine tasks. Adler et al. noted that such ambidexterity required "mindedness" on the part of employees as well as trust between employees and management.

Jordan and Graves (1995) suggested that flexibility could be maximized at minimum cost by designing the flexibility initiative at the strategic business unit level using a network of plants, rather than attempting to achieve the same level of flexibility within a single plant. Jordan and Graves used a model to demonstrate that assigning production of every model to two plants instead of one achieved almost the same level of ability to respond to demand changes as assigning all models to all plants, but with substantially minimized disruption to production.

McCreery et al. (2004) did a simulation study of the impact of three workforce management practices (configuration of work teams, cross training, and deployment of workers) on successful increases in mix, volume, and product flexibility. Zhang et al. (2006) investigated the impact of technology and operation improvement practices on flexible manufacturing competences. Avittathur and Swamidass (2007) claimed that profitability depended on the ability of firms to match their flexibility to that of their suppliers.

The "Rigid Flexibility" model developed by Collins et al. (1998) proposed that flexibility was best achieved, somewhat counterintuitively, through striving for simplicity and discipline. Their model results were confirmed empirically by da Silveira (2006). On a similar note, Khazanchi et al. (2007) proposed that innovation requires an emphasis on process control.

Given the trade-offs involved in increasing flexibility, as well as the relatively complex task of translating a flexibility initiative into the necessary systems and structures, increases in flexibility may not lead to increases in performance, even in situations where the market appears to reward flexibility. Also, the Rigid Flexibility model offers a reminder that a small amount of targeted flexibility in a manufacturing environment that is highly disciplined may outperform a larger amount of flexibility that is less controlled and disciplined. This should be kept in mind when developing systems and processes to measure flexibility, as the 
relationship between flexibility and performance is far from clear. Following Pagell and Krause in conjunction with the other studies mentioned above, we propose:

Proposition 2 Manufacturing flexibility is not directly related to flexibility outcomes. Increases in manufacturing flexibility may lead to a reduction in flexibility outcomes, and reductions in manufacturing flexibility may lead to improved flexibility outcomes.

\subsection{Operational flexibility}

Being technically or theoretically capable of varying the process is only the first step toward achieving flexibility (Jaikumar 1986; Upton 1995a, b, 1997; Jack and Raturi 2002). Even companies that have invested in increasing manufacturing flexibility can fail to achieve the competitive benefits of this increased flexibility. Narashimhan et al. (2004) differentiated between flexibility and execution competences in a two-stage model, noting that the ability of firms to reap the benefits of flexibility competences depends on execution competence. In this section, we review the implementation issues of process consistency and the role played by labor in flexibility.

\subsubsection{Process consistency}

The rigid flexibility model is related to the concept of process consistency, which is required for uniformity. Consider a situation in which a manufacturing organization has developed process documents (also known as standard operating procedures) for each operation. The next question is whether workers will follow these procedures in carrying out their tasks. The motivational implications of requiring workers to follow process documents are controversial (e.g., Adler et al. 1999; de Treville et al. 2005; de Treville and Antonakis 2006). This issue is outside the scope of this paper. What is clear, however, is that having workers perform tasks in a variety of ways tends to lead to uncontrollable process variability (Edelson and Bennett 1998). Interestingly enough, workers - and managers - tend to become more resistant to the discipline involved in process documentation as the rate of process change increases, as occurs in a flexibility initiative (Edelson and Bennett 1998). Process consistency also requires consistency in other aspects of process management, such as how equipment is maintained, information is collected from the process and analyzed, and how changes are made to the process. A lack of process consistency can cause poor flexibility outcomes, even in a situation in which the flexibility initiative is well matched to the competitive demands on the firm.

\subsubsection{Investment in lead time reduction}

Long manufacturing lead times substantially reduce flexibility. Cutting manufacturing lead times requires reduction of bottleneck utilizations, production lot sizes, and variability of interarrival times and processing rates (Suri 1994, 1998; de Treville et al. 2004). Reduction of setup times contributes to shorter lead times 
through permitting lot size reduction, and it therefore increases mobility. Lead time reduction-related flexibility also can be achieved through addition of a capacity buffer (Graves 1988; Jack and Raturi 2002) and through cellular manufacturing (e.g., Suri 1998). In cases where the objective of flexibility is to match production to demand, lead time reduction by itself may generate most of the flexibility required while minimizing disruption and cost (de Treville et al. 2004). Furthermore, long lead times make it more difficult for companies to produce to order rather than to stock, increasing the probability of supply chain mismatches as the number of product varieties increases.

Lead times are also affected by location decisions. A firm that produces in a lowlabor-cost country far away from its market will normally experience longer lead times due to distance and the large lot sizes that are normally required in such countries.

Proposition 3 The relationship between the flexibility strategy and flexibility outcomes is moderated by process consistency and investment in reducing manufacturing and supply chain lead times (see Fig. 2).

\section{Methodology}

This project began in a company ("Xygma") that was having problems with increasing its flexibility. As we observed these difficulties, we turned to the literature on flexibility and related topics. Not only did we want to make full use of existing academic knowledge, but it also seemed to us that the people in the company-generally well trained in management-should have had more of the knowledge necessary to avoid some of the difficulties. Looking for literature while focused on a real situation caused us to search, interpret, and integrate in a completely different fashion. Furthermore, the company situation encouraged us to look at literature from outside the area of flexibility, or even operations management, following calls by authors such as Stuart et al. (2002) and Ketchen and Hult (2006). After many iterations, we observed that grounding our literature review in the case had led us to a new understanding of what it means to set a flexibility strategy and use it to gain competitive advantage, and that the resulting model was potentially useful to practitioners.

Noting the limitations of deductive theory development in capturing the richness and complexity of phenomena observed in the field of operations management, Lewis (1998) proposed that systematic iteration between case data, literature, and the theorist's intuition could lead to theory development that was more creative, more useful, and of higher validity than theory development based solely on literature and intuition. Similarly, Stuart et al. (2002, pp. 421-422) emphasized the important role of cases in operations management theory development: "Case studies should not be seen as a methodology appropriate only for understanding and preliminary stages of theory development. Because of their observational richness, they also provide a means of refutation of, or extensions to, existing concepts" (see also Eisenhardt 1989). In particular, we argue that case-based work can facilitate theory integration that makes theory more accessible to practitioners, identifying 


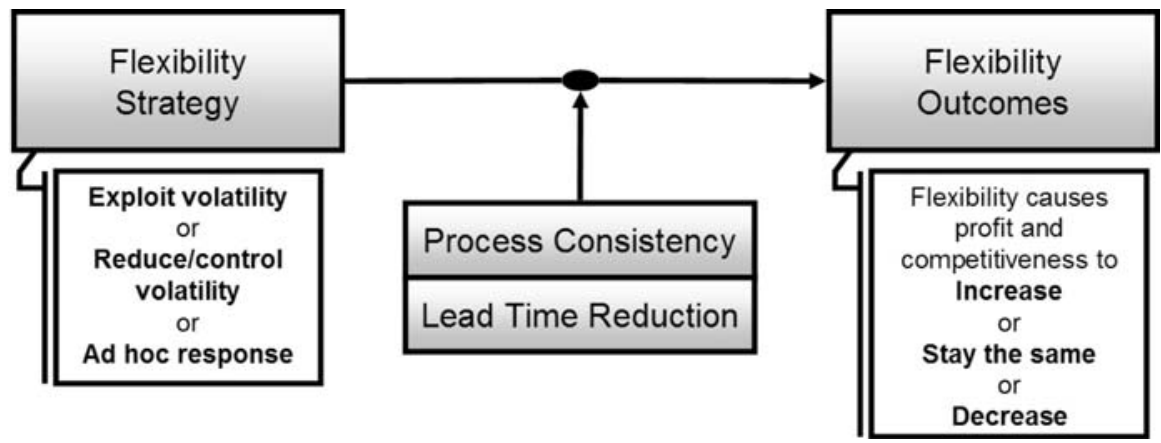

Fig. 2 A theoretical model of the relationship between the flexibility strategy chosen and flexibility outcomes, moderated by performance with respect to process consistency and lead time reduction

implementation issues, and ensuring that practice-based questions are considered in research design. Our intent was not to generalize from this specific case, but to use it as a catalyst to increase our creativity in identifying and integrating literature from various sources.

The iterative triangulation methodology calls for a different role of the case from that proposed by Eisenhardt (1989), who suggested to begin with a research question and then seek appropriate cases. Stuart et al. (2002) admitted that the research question may need to be adjusted given the actual case company situation. The problems that we observed in the company helped us to form our research questions. We began with the difficulties that we observed Xygma to be experiencing in aligning its manufacturing practice, manufacturing strategy, and business unit strategy. During the research process, the basic research question developed from "Why is there a mismatch between manufacturing behavior, manufacturing strategy, and competitiveness?" to "How does flexibility theory apply to this specific situation and context?" to "What other literature should be added to the flexibility literature to address Xygma's problems with its flexibility initiative?" to "What are the factors that influence the choice of flexibility strategy and the flexibility outcomes that result?"

Amundson (1998, p. 357) described theory- "how the researcher (or practicing manager or observer) interprets phenomena of interest" - as a lens that can be used to bring an environment into focus, stating that this approach is particularly relevant in the context of operations management research. Following Amundson, we conceptualized articles on the topic of flexibility as a set of lenses, evaluating each on its ability to bring case issues into focus. We began with a problem observed in the case, sought relevant articles, re-evaluated the problem from the perspective of the articles, reviewed the choice of literature, returned to the case, and so on. We referred to each transition from case to literature to intuition and back as an iteration. After several iterations, we found that our understanding of the case had increased substantially by observing through this set of lenses. Moreover, the act of using the theory as a lens gave us new insights into how to apply the theory to practice and how to integrate various pieces of theory into a combined theory unit. Our intent was not to add to the flexibility theory, but rather to use multiple 
iterations between the case and the literature to structure information and make it more readily available to practitioners, simultaneously allowing the case challenges and issues to drive the choice of literature considered. Interestingly enough, much of the directly relevant literature came from outside the area of flexibility research.

Whereas cases are typically used to test, refine, or develop a pre-specified theory, we did not come into the project with the objective of using the case to test existing theory. Our objective was to find what knowledge already existed and do a better job of applying it to practice. Given the complexity of the operations management environment, it is necessary to very briefly lay aside positivist approaches to permit richer reflection (Stuart et al. 2002). This does not at all mean that we reject the scientific method. The reflection period serves to allow us to evaluate and refine our research questions from the viewpoint of practice. The outcome of the reflection for us was a set of testable propositions that are subject to the scientific method like any others.

The case that motivated the theory integration done in this paper stems from a 4month internship during which one author was a participant-observer at the company described in the case that is briefly summarized in the next section. ${ }^{2}$ During the internship, the participant-observer witnessed inconsistencies between what actually occurred on the factory floor, the manufacturing strategy as specified by management, and the competitive environment, eventually concluding that efforts to increase flexibility were responsible for much of the mismatch. In evaluating Xygma's flexibility initiative, questions arose at three levels of analysis: (a) strategic, (b) tactical, and (c) operational. Questions at the strategic level suggested a relatively long time horizon and concerned defining and valuing flexibility as well as matching the level of flexibility to the environment. At the tactical level, issues arose concerning choice of technology and equipment, systems, and employee training. At the operational level, the main issues concerned maintaining process consistency, worker morale, and trust between workers and management in the face of the increased variability and conflicting demands arising from flexibility.

We did not look for an "average" case but took advantage of finding ourselves in an exemplary situation to facilitate a theoretical, rather than an empirical, generalization (see Upton 1994; Stuart et al. 2002). In working with an exemplary company, we took the risk that the results might not be generalizable. The decision about generalizability, however, is made not during the proposition phase, but during subsequent testing. Although the model extension that we developed after many iterations was useful in evaluating the situation that we observed, this does not guarantee that the company situation is sufficiently representative of the flexibility challenges faced in practice to make the model interesting across larger contexts. In order to gain an initial appreciation of the potential usefulness of the model, we evaluated three well-known Harvard Business School cases according to the model. The three cases were coded according to the model by two of the authors working independently.

\footnotetext{
${ }^{2}$ The full case was described in a 60-page unpublished and confidential report submitted as part of the internship.
} 


\section{The Xygma plant}

Our story revolves around a plant owned by a major producer of construction materials that was struggling to increase manufacturing flexibility. On one hand, the company's management was committed to serving the customer quickly and responsively, and hence had made the decision to respond to customer requests that product dimensions be customized, requiring an increase in manufacturing flexibility concerning the range of the product, as well as the mobility in switching between products (Upton 1995a). On the other hand, manufacturing personnel felt that this policy was expensive-as such products cost more money to produce but did not command a price premiumand disruptive to production. The flexibility initiative was causing the frequency of customized orders - currently at $20 \%$ of volume - to increase, and complaints about quality problems were increasing as well. In addition, some observers noted that Xygma's range and mobility were much less than would have been expected given the specifications of the equipment in the plant.

The Xygma plant had been designed from the start to be flexible. The plant itself was small, which limited the size of the equipment that it could contain. Also, the parent company had decided, given the weight of the products, to place a plant in each market area to avoid expensive transportation. Each plant was expected to be able to respond to the needs of its market area without having to resort to output from other plants.

The Xygma plant's attempt to be more responsive to customers began with the decision to begin customizing the dimensions of the product to customer specifications. Production of customized products was normally expected to follow the standard process, with the machines set up to the dimensions required. Because of the setup times involved, however, supervisors had developed an alternative technique: Rather than producing parts of the correct dimension, standard products were cut to the required size. The advantage of this approach was that it avoided two equipment setups. The disadvantages, however, included (a) substantial quantities of work-in-process inventory in the aisles awaiting the new cutting operation, (b) that the cut product had not been approved by engineering and was not subject to the same tests and quality assurance, and (c) that operators not following standard procedures risked creating a major increase in process variability, as well as loss of the ISO 9000 series certification that the plant had recently obtained.

A second flexibility-related issue concerned production scheduling. Although the decision to customize the dimensions of $20 \%$ of the production appeared modest, its impact on scheduling was substantial, particularly given management's desire to increase the plant's capacity utilization to the $95 \%$ level often achieved prior to the increase in flexibility. This scheduling problem manifested itself in three ways: (a) stress and lack of time for the production planner, who was spending more than half of his time trying to generate a workable schedule; (b) overstock of some products and stockouts of others; and (c) general confusion, which propagated to the warehouse, resulting in misplaced stock and delivery errors.

Although the lengthy setup times encouraged large lot sizes and the unauthorized procedures for customizing dimensions described above, as well as complicating scheduling, plant personnel showed little interest in reducing setup times. In 
discussions, company personnel claimed that investment in setup time reduction would be too costly and take too much time, but when pressed admitted that setup times could have been cut in half for a modest investment.

The market for Xygma's product was changing. New opportunities and customer needs were emerging as technological product innovation created new opportunities to meet customer needs. The parent company had an active research group that was considered to be at the forefront of product development in these areas; however, Xygma was neither considering adding the resulting products to its product line nor working together with corporate management to develop new production processes for eventual new products. The sense within the plant was that personnel had all the work that it could handle with offering products with customized, rather than standard, dimensions.

Finally, relationships between workers and management were increasingly conflictual. Workers felt that they were simultaneously required to produce efficiently and to deal with constant change. Workers also felt torn between the need to produce high-quality materials and the need to get product out the door to customers. Training was another source of conflict: Workers received limited training and were expected to learn on the job, but as a result of the flexibility initiative, they were required to have more skills and to acquire new skills more quickly. Management, however, felt that increasing training would be too expensive and would take too much time.

A year after the flexibility initiative began, plant decision makers were having serious doubts concerning whether the initiative was worth pursuing. Costs had risen, the expected increase in customer satisfaction was considerably less than expected, workers were unhappy, and the atmosphere on the shop floor was not conducive to growth and development. No one had time to think or plan for the future. Obviously, there was a trade-off between flexibility and efficiency, but it appeared to management that this trade-off was heavily weighted toward loss of efficiency, with little gain in flexibility and the benefits flowing from it.

As mentioned previously, Xygma's flexibility-related problems emerged at three levels of analysis: (a) strategic, (b) tactical, and (c) operational. At the strategic level, although Xygma's original strategic positioning as a flexible plant appeared to have been reasonable, the plant's efforts to respond to uncertainty in its environment appeared ad hoc and reactive, consistent with management's passivity in scanning and interpreting the environment combined with a complete lack of any effort to analyze or make sense of the environment. Xygma often failed to capitalize on volatility in the environment that could have been exploited to improve its competitive advantage, such as changes in product characteristics that would allow the product to better meet customer needs and that Xygma was particularly well placed to address. The willingness to respond to customer requests for customized products without fully evaluating the demands that would be placed on the environment also appeared to represent a less-than-optimal match between environmental uncertainty and manufacturing flexibility. At the tactical level, flexibility as perceived by the customer was not being translated into the resources, systems, and structures required for its realization, and the cost of flexibility outweighed the benefits. The plant and company, for example, could have used a network of plants to reduce the cost of flexibility, as proposed by Jordan and Graves 
(Upton 1994, p. 1995), or could have performed a House of Flexibility analysis, as proposed by Olhager and West (2002), to more clearly specify the flexible competences required to accomplish their mission. Finally, at the operational level, the increased production variability from the flexibility initiative project was creating problems in maintaining process consistency, worker morale, and trust between management and workers. Furthermore, their ability to match production to customer demand would have been greatly increased by investing in lead time reduction without requiring more disruptive and costly aspects of increasing flexibility (de Treville et al. 2004).

\section{The model}

\subsection{Model presentation}

Our extension of the Daft and Weick model is presented in Fig. 3. Firms invest in scanning and interpreting the environment with differing degrees of intensity, reflected in their search behavior, allocation of resources to searching and interpreting, and their efforts to acquire search and interpretation skills (Daft and Weick 1984). Activity in scanning and interpreting the environment influences the flexibility strategy that is chosen by the organization, with flexibility strategies defined according to how the organization treats volatility: exploitation, reduction or control, or lack of specific policy.

This relationship is moderated by whether decision makers in the organization believe that the environment is analyzable or not. Do managers believe that there is a right answer that can be determined by rational analysis, data collection, linear thinking, and logic? Or do they believe that many possible solutions exist, and that the organization can interact with the environment to shape it, which in turn requires more emphasis on judgment, intuition, and improvisation (Daft and Weick 1984)? Following Daft and Weick, we propose that activity in combination with a belief that the environment is unanalyzable results in a flexibility strategy that is positioned to extract value from environmental volatility. In the absence of active scanning and interpretation, however, the organization loses the benefit of the rational and linear analysis while being buffeted by uncontrolled intuition and individual judgment.

The flexibility strategy then translates into flexibility outcomes (that is, the impact on competitiveness and profitability that results directly from the firm's experience of uncertainty and volatility in its environment). This relationship is moderated by the organization's efforts, activity, and investment in process consistency and lead time reduction. Process glitches and long lead times can bring defeat from the most brilliant flexibility strategies.

\subsection{Cases}

We chose three well-known teaching cases to do an initial test of the extended model:

- Eli Lilly and Company: The Flexible Facility Decision (1993) (Pisano and Rossi 1994) 


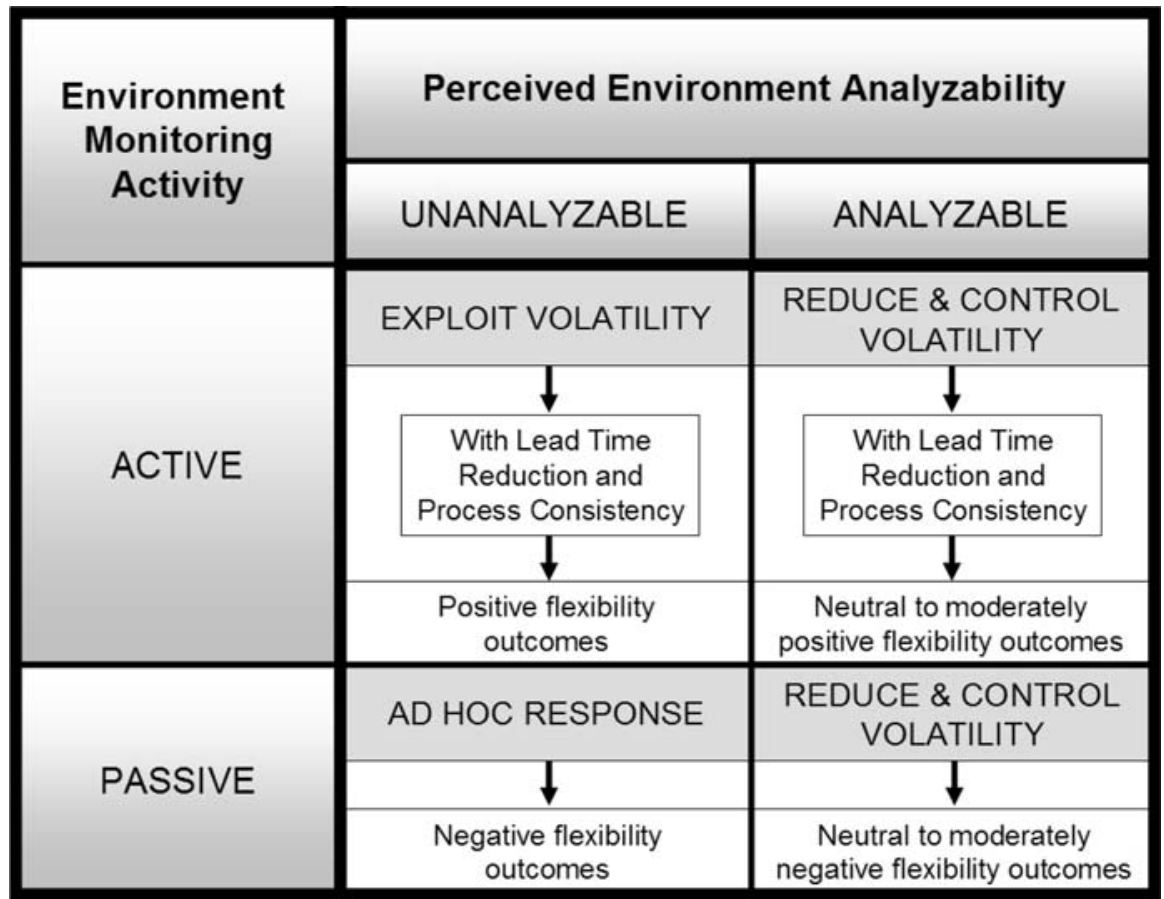

Fig. 3 The Daft and Weick (1984) model of organizations as interpretation systems, extended to the context of operations flexibility and incorporating the theoretical relationships portrayed in Figures 1 and 2

- Stermon Mills Incorporated (Upton 1993/2001)

- Zara: IT for Fast Fashion (McAfee et al. 2004/2007)

In this section, we briefly review the cases. We then discuss how we coded each construct across the cases, including the Xygma case.

\subsubsection{Eli Lilly and Company: The Flexible Facility Decision (1993)}

The Eli Lilly case describes a decision concerning whether to invest in flexible manufacturing capacity in the face of pressure to reduce time to market. Historically, the company had constructed plants that were dedicated to relatively few products and that had difficulties in shifting to new products. Students are asked to put themselves in the position of the manager of strategic facilities planning in weighing the considerable increase in cost of the flexible facility versus the ability to postpone decision making until more information concerning which products would succeed would be available in the market.

\subsubsection{Stermon Mills, Incorporated}

Stermon Mills faced a situation in which survival depended on becoming more flexible in terms of the range of products offered to customers. Students are asked to consider what will be required operationally to increase flexibility in terms of both 
actions and cost, and to evaluate feasibility and attractiveness. Increasing range flexibility in the case also requires increasing mobility and uniformity through streamlining setup procedures.

\subsubsection{Zara: IT for Fast Fashion}

Zara competes on the unpredictability of fashion. As a new style emerges, Zara is poised to produce and distribute it very rapidly. The case describes Zara management deciding whether to maintain an ancient technology that is completely predictable or instead to upgrade to a more current technology, risking distracting management from their primary focus. Zara is an example of extracting value from volatility.

\subsection{Coding of constructs}

\subsubsection{Activity in scanning and interpreting the environment}

The cases evaluated give a range of activity levels. Zara is clearly the most active in scanning and interpreting the environment. Senior management is actively involved in data collection and interpretation. Zara's intent is clearly to shape their competitive environment, which they have consistently done over the history of the company. Eli Lilly and Stermon Mills, in contrast, display activity only when threatened by changes in the competitive arena. The activity displayed is not intended to radically reshape the environment. Both companies are described in the cases as accepting the environment as is and making the required changes. Eli Lilly, for example, could have considered a strategy that would have used flexible manufacturing capacity to substantially increase the number of products tested. Stermon Mills could have considered a campaign that would encourage customers to come up with new types of paper, rather than become somewhat more responsive to the range of paper types already requested by customers. We therefore coded Eli Lilly and Stermon Mills as moderately active, with Stermon Mills slightly higher as they were defining their competitiveness more explicitly on their flexibility, as well as because they were fighting for their survival.

Xygma, at the time of our observation, was acting in a passive way, accepting the environment and making no attempt to either shape it or manage it through analysis.

\subsubsection{Analyzability}

Zara is described in the case as being ready for a wide variety of states of nature. Whatever unusual style a momentarily famous person might make briefly fashionable, Zara is ready for it. The effort is not to forecast ex ante what styles will emerge and make them to stock, but to produce whatever ends up being demanded. We therefore coded Zara as demonstrating a belief that the environment is unanalyzable with respect to product demand.

Eli Lilly and Stermon Mills demonstrate much more effort to collect data, analyze, and use linear thinking to come up with an optimal solution. The actions of 
decision makers in these two cases are consistent with a belief that the environment is analyzable, so we coded them accordingly.

Xygma showed no evidence of a belief that the environment could be analyzed.

\subsubsection{Flexibility strategy}

We coded Zara as seeking to exploit volatility in the environment. Eli Lilly and Stermon Mills used flexibility to reduce and control their exposure to volatility rather than using it to increase profit or competitive advantage. Xygma showed the absence of a flexibility strategy, being buffeted by volatility both internally and externally.

\subsubsection{Process consistency and lead time reduction}

The Zara case demonstrated the company's commitment to both process consistency and lead time reduction. The case decision stemmed from management's desire to reduce technology risk that did not explicitly increase their flexibility, indicating an emphasis on process consistency. Lead times were controlled by keeping manufacturing in Spain, a counterintuitive decision at a time when most competitors were shipping production offshore to reduce cost.

Both Eli Lilly and Stermon Mills indicated moderate attention to process consistency and lead time reduction. Process consistency and lead time efforts did not drive, but were sufficient to avoid derailing, their flexibility efforts.

Xygma substantially underinvested in both process consistency and lead time reduction, thereby losing any hope of gaining advantage from their efforts to increase flexibility.

\subsubsection{Flexibility outcomes}

We coded a flexibility outcome as neutral if the flexibility initiative protected the company from losing competitiveness and profit from increases in volatility. Zara's flexibility outcomes were coded as extremely positive, given the company's profits and competitiveness that appear to be directly attributed to flexibility. Eli Lilly and Stermon Mills appeared able to compensate for increased volatility through their flexibility initiative, but they did not appear likely to become more competitive or profitable, so we coded their flexibility outcomes as neutral. Xygma was paying dearly for its foray into flexibility, so we coded their flexibility outcomes as negative.

\subsection{Model outcomes}

The outcomes of our testing are summarized in Table 1 and illustrated in Fig. 4.

\section{Summary and conclusions}

This research project began with the observation that Xygma's manufacturing strategy was not well matched with the business unit strategy, with Xygma's efforts 
Table 1 Coding of the model constructs for each of the cases analyzed

\begin{tabular}{lllll}
\hline Construct & \multicolumn{2}{l}{ Case } & & \\
\cline { 2 - 5 } & Zara & Eli Lily & Stermon Mills & Xygma \\
\hline Activity & Active & $\begin{array}{c}\text { Passive, then } \\
\text { moderately active }\end{array}$ & $\begin{array}{c}\text { Passive, then } \\
\text { moderately active }\end{array}$ & Passive \\
$\begin{array}{l}\text { Perceived environment } \\
\text { analyzability }\end{array}$ & Unanalyzable & Analyzable & Analyzable & Analyzable, then \\
Flexibility strategy & Exploit & Reduce and control & Reduce and control \\
Lead time reduction & Yes & volatility & Ad hoc response \\
Process consistency & Yes & Yes & Yes & No \\
Flexibility outcomes & Very good & Neutral & Yes & No \\
\hline
\end{tabular}

to increase manufacturing flexibility apparently a major cause of the mismatch. We divided the flexibility-related difficulties facing Xygma into the strategic, tactical, and operational levels of analysis. For each level of analysis, we searched for literature that was relevant to the difficulties that we observed. We began with more classic flexibility literature, but as we applied this literature to the Xygma case, we discovered interesting links that took us well outside the flexibility domain. As we iterated between the case and literature, we discovered that Daft and Weick's (1984) model was helpful in explaining why Xygma's flexibility initiative was not succeeding: Much of the problem stemmed from how the company scanned and interpreted the environment. As proposed by Swamidass and Newell (1987), the company was responding to uncertainty in the environment by increasing manufacturing flexibility, but its undirected viewing approach resulted in a lack of flexibility strategy. Xygma worked neither to reduce and control, nor to exploit, the uncertainty and volatility in the environment.

Evaluating Xygma's situation through the lens of the Daft and Weick (1984) model gave insights into Pagell and Krause's $(1999,2004)$ paradoxical results concerning the relationships between uncertainty in the environment, manufacturing flexibility, and performance. Extending Daft and Weick's model, we suggest that the constructs of activity in scanning the environment and perceived analyzability are useful in explaining the choice of flexibility strategy and the resulting performance.

Although the literature contains much normative information concerning how to translate an increase in manufacturing flexibility into the technologies, systems, and structures required, as well as how to reduce the loss of efficiency arising from increased flexibility, we did not observe any of this knowledge being put into practice at Xygma, which supported our assumption that a theory-practice gap existed. Similarly, readily available information concerning lead time reduction, setup time reduction, production scheduling, process documentation, and the importance of running the process as specified in the process documents was not applied at Xygma. Under these conditions, efforts to increase flexibility are not likely to result in positive flexibility outcomes.

Reviewing the flexibility literature while constantly iterating with the Xygma case opened our eyes to new articles and helped us to see connections to literature 


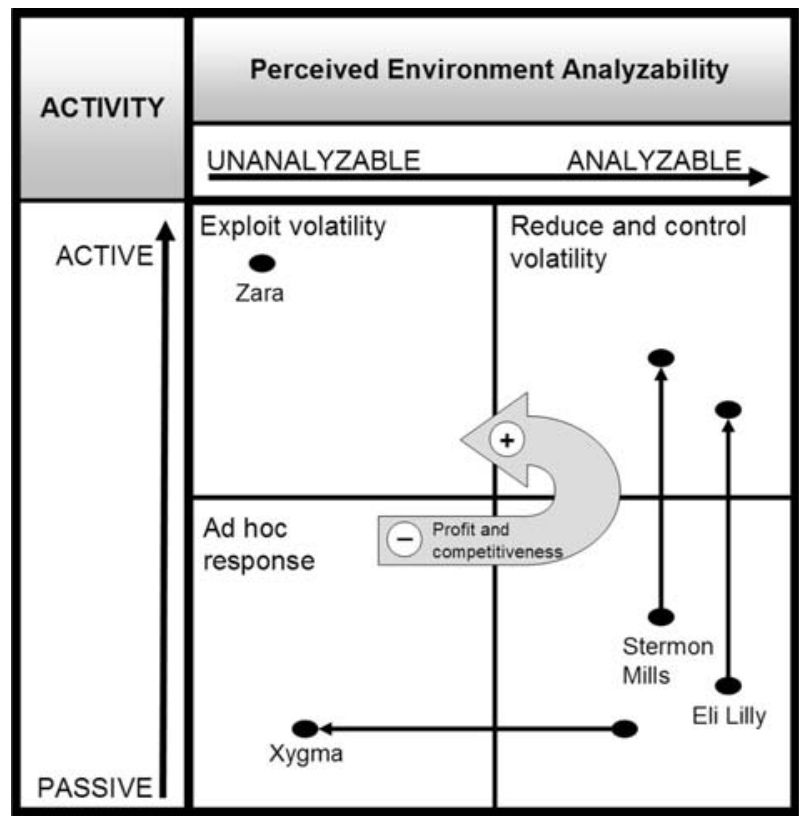

Fig. 4 Mapping of the cases analyzed onto the extended Daft and Weick (1984) model, demonstrating positioning and outcomes

that we would not otherwise have considered. It also caused us to refine our research questions so as to integrate the literature into an extension of Daft and Weick's model that may be useful to practitioners. Grounding our theory integration with the case study made it more likely that our work would contribute to bridging the gap between theory and practice, and it also should encourage evidence-based practice in the area of flexibility, as we simultaneously brought real questions from practice to theory, as well as digesting and synthesizing theoretically sound information from the literature to make it more accessible to practice. Initial testing indicates that the resulting model may be generalizable and that it warrants more extended investigation.

If our model is supported in further testing, what will be the implications for managers? First, any efforts to increase flexibility should begin with activity in scanning and interpreting the environment. No investment in flexible automation, for example, will pay off for a firm that has not done its work in getting to know the uncertainty in its environment. Second, decision makers should be pushed to think of a greater variety of states of nature and should be encouraged to search for volatility that might be exploited. Eli Lilly and Stermon Mills were able to overcome the danger of increased volatility through their efforts to increase the flexibility of their operations, but Zara has been able to achieve much more radical benefits. Note, however, that increasing the perception of unanalyzability without increasing activity risks ad hoc reactions rather than establishment of a flexibility strategy. Finally, companies that are emphasizing increasing flexibility should be 
strongly encouraged to emphasize process consistency and lead time reduction, even though increasing flexibility and precision simultaneously may seem counterintuitive. It is, after all, when academic research yields a result that is counterintuitive that it has the greatest potential value to practitioners. If all results were intuitive, who would need academic research?

\section{References}

Adler PS, Goldoftas B, Levine DI (1999) Flexibility versus efficiency? a case study of model changeovers in the Toyota production system. Organ Sci 10(1):43-68

Amundson SD (1998) Relationships between theory-driven empirical research in operations management and other disciplines. J Oper Manage 16(4):341-359

Avittathur B, Swamidass P (2007) Matching plant flexibility and supplier flexibility: lessons from small suppliers of US manufacturing plants in India. J Oper Manage 25(3):717-735

Browne J, Dubois D, Rathmill K, Sethi SP, Stecke KE (1984) Classification of flexible manufacturing systems. FMS Magaz 2(2):114-117

Cascio WF (2007) Evidence-based management and the marketplace for ideas. Acad Manage J 50(5):1009-1012

Chang SC, Yang CL, Cheng HC, Sheu C (2003) Manufacturing flexibility and business strategy: an empirical study of small and medium sized firms. Int J Prod Econ 83(1):13-26

Cohen DJ (2007) The very separate worlds of academic and practitioner publications in human resource management: reasons for the divide and concrete solutions for bridging the gap. Acad Manage $\mathbf{J}$ 50(5):1013-1019

Collins RS, Cordon C, Julien D (1998) An empirical test of the rigid flexibility model. J Oper Manage 16(2-3):133-146

da Silveira GJC (2006) Effects of simplicity and discipline on operational flexibility: an empirical reexamination of the rigid flexibility model. J Oper Manage 24(6):932-947

Daft RL, Weick KE (1984) Toward a model of organizations as interpretation systems. Acad Manage Rev 9(2):284-295

De Groote X (1994) The flexibility of production processes: a general framework. Manage Sci 40(7):933-945

de Treville S, Antonakis J (2006) Can lean production be intrinsically motivating? Contextual, configurational, and levels-of-analysis issues. J Oper Manage 24(2):99-123

de Treville S, Shapiro RD, Hameri A (2004) From supply chain to demand chain: the role of lead time reduction in improving demand chain performance. J Oper Manage 21(6):613-627

de Treville S, Antonakis J, Edelson NM (2005) Can standard operating procedures be motivating? Reconciling process variability issues and behavioral outcomes. Total Qual Manage Bus Process 16(2):231-241

Edelson NM, Bennett CL (1998) Process discipline: how to maximize profitability and quality through manufacturing consistency. Quality Resources, New York

Eisenhardt KM (1989) Building theories from case study research. Acad Manage Rev 14(4):532-550

Fine CH, Freund RM (1990) Optimal investment in product-flexible manufacturing capacity. Manage Sci 36(4):449-466

Gerwin D (1993) Manufacturing flexibility: a strategic perspective. Manage Sci 39(4):395-410

Graves SC (1988) Safety stocks in manufacturing systems. J Manuf Oper Manage 1(1):67-101

Handfield R (1993) A resource dependence perspective of Just-in-Time purchasing. J Oper Manage 11(3):289-311

Hauser JR, Clausing D (1988) The house of quality. Harvard Bus Rev 66(3):63-73

Hayes RH, Wheelwright SC (1984) Restoring our competitive edge: competing through manufacturing. Wiley, New York

Jack EP, Raturi A (2002) Sources of volume flexibility and their impact on performance. J Oper Manage 20(5):519-548

Jaikumar R (1986) Postindustrial manufacturing. Harvard Bus Rev 64(6):69-76

Jones N (1997) Industrie Pininfarina: the new customer decision. Ivey Publishing, London

Jordan WC, Graves SC (1995) Principles on the benefits of manufacturing process flexibility. Manage Sci 41(4):577-594 
Ketchen DJ, Hult GTM (2006) Bridging organization theory and supply chain management: the case of best value supply chains. J Oper Manage 25(2):573-580

Khazanchi S, Lewis MW, Boyer KK (2007) Innovation-supportive culture: the impact of organizational values on process innovation. J Oper Manage 25(4):871-884

Koste LK, Malhotra MK (1999) A theoretical framework for analyzing the dimensions of manufacturing flexibility. J Oper Manage 18(1):75-93

Koste LL, Malhotra MK, Sharma S (2004) Measuring dimensions of manufacturing flexibility. J Oper Manage 22(2):171-196

Lewis MW (1998) Iterative triangulation: a theory development process using existing case studies. J Oper Manage 16(4):445-469

Linderman K, Schroeder RG, Zaheer S, Choo AS (2003) Six sigma: a goal-theoretic perspective. J Oper Manage 21:193-203

McAfee A, Dessain V, Sjöman A (2004/2007) “Zara: IT for Fast Fashion” Harvard Business School case 9-604-081. Harvard Business School Publishing, Cambridge

McCreery JK, Krajewski LJ, Leong GK, Ward PT (2004) Performance implications of assembly work teams. J Oper Manage 22(4):387-412

McKay K, Pinedo M, Webster S (2002) Practice-focused research issues for scheduling systems. Prod Oper Manage 11(2):249-258

Melnyk SA, Handfield RB (1998) May you live in interesting times: the emergence of theory-driven empirical research. J Oper Manage 16(4):311-319

Narasimhan R, Talluri S, Das A (2004) Exploring flexibility and execution competencies of manufacturing firms. J Oper Manage 22(1):91-106

Olhager J, West BM (2002) The house of flexibility: using the QFD approach to deploy manufacturing flexibility. Int J Oper Prod Manage 22(1):50-79

Pagell M, Krause DR (1999) A multiple-method study of environmental uncertainty and manufacturing flexibility. J Oper Manage 17(3):307-325

Pagell M, Krause DR (2004) Re-exploring the relationship between flexibility and the external environment. J Oper Manage 21(6):629-649

Pisano G, Rossi S (1994) Eli Lilly and company: the flexible facility decision (1993) Harvard Business School case 9-694-074. Harvard Business School Publishing, Cambridge

Raj T, Shankar R, Suhaib M (2007) A review of some issues and identification of some barriers in the implementation of FMS. Int J Flex Manuf Syst 19(1):1-40

Rynes SL (2007) Editor's foreword: tackling the "great divide" between research production and dissemination in human resource management. Acad Manage J 50(5):985-986

Rynes SL, Bartunek JM, Daft RL (2001) Across the great divide: knowledge creation and transfer between practitioners and academics. Acad Manage J 44(2):340-355

Rynes SL, Giluk TL, Brown KG (2007) The very separate worlds of academic and practitioner periodicals in human resource management: implications for evidence-based management. Acad Manage J 50(5):987-1008

Sawhney R (2006) Interplay between uncertainty and flexibility across the value-chain: towards a transformation model of manufacturing flexibility. J Oper Manage 24(5):476-493

Sethi AK, Sethi SP (1990) Flexibility in manufacturing: a survey. Int J Flex Manuf Syst 2(4):289-328

Stuart I, McCutcheon D, Handfield R, McLachlin R, Samson D (2002) Effective case research in operations management: a process perspective. J Oper Manage 20(5):419-433

Suri R (1994) Common misconceptions and blunders in implementing quick response manufacturing. In: Proceedings of the SME AUTOFACT conference

Suri R (1998) Quick response manufacturing. Productivity Press, Portland

Swafford PM, Ghosh S, Murthy N (2006) The antecedents of supply chain agility of a firm: scale development and model testing. J Oper Manage 24(2):170-188

Swamidass PM, Newell WT (1987) Manufacturing strategy, environmental uncertainty and performance: a path-analytic model. Manage Sci 33(4):509-524

Trigeorgis L (1999) Real options: managerial flexibility and strategy in resource allocation. MIT Press, Cambridge

Upton D (1994) The measurement of manufacturing flexibility. Calif Manage Rev 36(2):72-89

Upton DM (1993/2001) Stermon Mills incorporated. Harvard Business School case 9-693-053. Harvard Business School Publishing, Cambridge

Upton DM (1995a) Flexibility as process mobility: the management of plant capabilities for quick response manufacturing. J Oper Manage 12(2):205-224 
Upton DM (1995b) What really makes factories flexible? Harvard Bus Rev 73(4):74-84

Upton DM (1997) Process range in manufacturing: an empirical study of flexibility. Manage Sci 43(8):1079-1092

Van Wezel W, Van Donk DP, Gaalman G (2006) The planning flexibility bottleneck in food processing industries. J Oper Manage 24(3):287-300

von Hippel E, Thomke S, Sonnack M (1999) Creating breakthroughs at 3M. Harvard Bus Rev 77(5): 47-57

von Ungern-Sternberg T (1990) The flexibility to switch between different products. Economica 57(227):355-369

Zhang Q, Vonderembse MA, Lim JS (2003) Manufacturing flexibility: defining and analyzing relationships among competence, capability, and customer satisfaction. J Oper Manage 21(2):173-191

Zhang Q, Vonderembse MA, Cao M (2006) Achieving flexible manufacturing competence - the roles of advanced manufacturing technology and operations improvement practices. Int J Oper Prod Manage 26(6):580-599

\section{Author Biographies}

Suzanne de Treville is Professor of Operations Management and Dean of the Faculty of Business and Economics at the University of Lausanne. Her research interests concern the implementation and competitive implications of lead time and process variability reduction in operations. She publishes in journals such as the Journal of Operations Management and Interfaces. Professor de Treville completed her doctorate at the Harvard Business School, and her masters and undergraduate studies at Carnegie-Mellon University.

Samuel Bendahan is a doctoral student in Organizational Behavior at the Faculty of Business and Economics at the University of Lausanne. His research interests are primarily concerned with leadership and performance.

Annelies Vanderhaeghe completed her Master of International Management at the Faculty of Business and Economics at the University of Lausanne and is now working for the Picanol Group. 